\title{
INTERNET GAMBLING AND CRIME
}

\section{Introduction}

It is often remarked that crime always follows money. With this in mind it should be obvious that the Internet is not inmune to this generally held betief. However, new technology and virtual money brings with it new problens. According to recent reports (BBC News Online, 1998), the British Police are increasingly concerned abont virtual casinos. The Computer Crime division of the police has expressed concerns that there atre no guarantees with online gambling games that they are played fairly, and that gambless giving credil card details could be putting themselves at financial risk. Such casinos offering on-screen games such as roulette and blackjack are actually illegal in the UK. However, most virlual casinos are based offshore which is problematic in terms of policing and regulation.

More recently, one woman in the US amassed $\$ 70,000$ of gamblitig debt through online gambling but she is now exploiting the illegalisy issue by counter-suing the Internet betting companies, saying that the transactions between them were technically unlawful, thus repayment of her debts is unenforceable. This is likely to become a test case over the use of credit card transactions by online gambling sites - a melhod of payment which is ultimately the key to the survival of these virtual gaming sites. Just from these opening comments, it is clear that Internet gambling provides new challenges for police and regulators.

\section{A Brief Overview}

The field of gambling is not immune to the technological revolution taking place elsewhere in other fields. Further to this, technology has always played a role in the development of gambling practices and will continue to do so, particularly with the growth of hnternet gambling. No one is really sure how the Intemet will develop over the nexi five to 10 yeats but Internet ganbing as a commercial activity has the potential for large financial rewards for the operators. Some observens predict that Internet casinos and the online ganing community could become a \$10. 25 billion indistry by 2001 yet atlegtate regtiation is not in place (Dwek, 1997: GamCare News, 1998). However, the most recent detailed andysiss suggests that by the year 2001 , whe fotemo ganbling industry will be a $\$ 2.86$ billion industry (Datamonitor. 1998). Is has to be satid hat to be said that Interne gambling is still in its infancy bu lhings are changing fast.

it is estimated that by 2001 , Jotteries will aceoum for $58 \%$ of Internet gambling with the rest of the matket being taken up by hose lacing/event betling $(28 \%)$, casinos $(8 \%)$, elecuronic scratch cards/ganing mathines (4\%) and bingo (3\%) (Datamoluitor, 1988). The success of atambling slepends on many factors including diversity, alressibility and advertising. lnterned gambling is provided by a 
network of networks that span geographical burlers int are not discrete. Internet gambling is therefore global. accissibte and has 24.tootr avalability.

Gambling is molergoing mass expansion all over ilte workl. The global growth of gambing is particulatly noteworthy it the area of Internet gambling. In many countries there appeass to be a slow shift from gambling being taken out of gambling environments and into the home and the workplace (and in the case of interne gambling it has gone from being very site specific to being in cyberspace). This trend has been noted by a number of authors (ev, Eaklington, 1998; Griffiths. 1998; MacMillen, 1998).

\section{Social Issues}

The rise of Internet gambling will provide both marketing opportunilies and narketing theals. This wilt have implications for onler fortus of gambling and existing licence-holders. Some parts of the ganning industry will almost certainly lose market share. Many may start to set up their own Internet gambling sites because the initial set-up costs will be minimal in comparison to (say) a casino. This will have implications for the social impact of Internet gambling.

Today's gambler call gamble in a variety of places including casinos, betting shops, amusement arcades and bingo halls. Most of these types of ganbling are currently available in some form on the Internet so why - when people eventually go online -- will they want to move from the privacy and comfort of their own home?

Some observers (eg, O'Neill, 1998) have argued that Internet gambling provides "a natural fit for compulsive gamblers". However, there are some problems. According to Tottenham (1996), these problems include those of a technical, managensent and regulatory nature. However, over time, the Internet will become technologically more sophisticated allowing faster speeds and better graphics etc. and issues surrounding security and marketing will be tightented up. There are also issues suclk as:

Underage gambling - Ilow can you be sure that adolescents do not have access 10 Interne1 gambling by using a parenl's credil catte?

Gambling while imforicated - How can you be sure that a person does not have access to Internet ganbling while they are under the influence of alcohol and/or other drugs?

Internet gambling in the workplace - Internet gambling is one of the newer opportunities for gambling in the workplace. An increasing number of organizations have unlinited Internet access for all employees and many employees have their own computer terminal in their own office (eg, higher education) which allows stich activity to take place withott atrousing suspicion. Like telephone belling, finemet gambling is a somewhat solitary activity that can happen without the knowledge of both management and the employee's co-workers.

Opening howrs -- The Internet never closes so it is theoretically possible 
to gambie all day every day!

Trist-How can a gambler be sure that operators in other countries will honour wagers made? How can the gambler be sure that the virtual casino will not close down suddenly and take all the customer's moncy?

All these social concerns raise questions. Is it now time to draw the line? Have we gone too far? What is the community benefit of Internet gambling? The issue of Intemel gambling (particularly in places like Austratia which have already legalized Internet gambling) has received very liztle in the way of public debate. It is quite obvious that the driving force behind Internet ganting is not consumer demand but market supply. The gaming industry is itself setting the pace.

\section{An International Perspective}

There appears to be differen attitudes in different countries with respect to the threat of Internet gambling. In some countries (eg, US) there appears to be the beginnings of a backlash bordering on prohibition. On the other end of the spectrum we have Australia, New Zealand and Canada who appear to be very liberal in their attitude and who are all considering legalization or have done so. Then there are those countrics who are liberal without doing anything proactive (eg, UK). However, the Gaming Board of Great Britain has at least acknowledged that because the Internet can cross any border it can be exploited by organized crime. The European Commission has only just begun to look into the issue.

But how many gambling sites are there? Estimates put the number of online gaming sites at aboui 600 with about 300 concentrating on lotteries (Dwek. 1997). There are, bowever, disagreements about the actual number. For instance, Laiho (1998) estimates there are between 250-1000 websites although he does admit that some (and perthaps ever mosi) are not involved with actual gambling. O'Neill (1998) estimated that there were about 160 acual cash gambling sites as of Jine 1998 and according to MacMilien (1998) illegal gambling on the Internet in the US has increase ten-fold.

\section{- Internet Gambling and Policy Options}

lnternet gambling provides a challenge for the police and regulators. It perhaps slould be remembered that legislation will not control the technology which is getting better all the time. J egislation is not just about the Internet. For instance, interactive television ganbling (tosing the remole control to make bets) is going to be impossible to regulate and police. This could be a family activity! According to McMillen (1998), there are three basic policy approaches:

(1) "Laissez faire" appmach: This involves a self-regulatory liberal approach and should not be left to the matket.

(2) Prohibitive and restrictive approach: For some (eg. US, Singapore) this appears to be a knee-jerk reaction but how car 
this be enforced? This is not a realistic option paticularly becatuse it involves ctoss-border (state and country) gambling. Such a situation represents a fundamentally different kind of gambling 10 regulate. Prohibition has traditionally led to increases in organized crime. What's more, as we highlighted at the beginning of this article, crime follows money. The reality is that advancement in computer technology generally, and the increased availability of the Intentet in particular, hats provided for new innovations in, and an expansion of, the field of criminality.

(3) Pragmatic approach: This is the most realistic approach and has been adopted in Australia (and will be examined in the next section). It could be argued that this is just opportunistic with various parties capitalizing on market advantage. (There is no doubt that entrepreneurs will certainly try to cash in such a market.)

\section{Case Study: The Australian Response}

The Australians have a had what could be called a head start in the area of Intemet gambling and recently legalized it. They are working under a Draft Regulatory Control Model, which has some principle objectives and components that work within their gaming legislation. Because Australia has a number of cross-jurisdictional boundaries they have tried to take a common stance but allowing each member state to be flexible thus allowing diversity to occur. This they see as the best kind of federalist working practice. Some of the key elements of the Australian approach are set out below:

- working within the gaming legislation

- each state to licence the operations

- each state to approve premises and games

- games to be specific to the operator

- games to adhere to specific sets of rules (set in advance)

- hardware and software to be certified

- regulators can withdraw games that are against the public interest based on research

- all malfunctions will lead to bets being refunded

- operator will be prosecuted for using defective equipment

- regulators can enforce operator's intentions of the game

- all transaction records are kept for seven years

- tax is paid in the state of the player

- it is up to the operator to protect against underage gambling

These guidelines are to help prevent "shady" practices (eg, operators can easily manipulate their games to exploit the players). The Australian response can be compared with responses elsewhere. For instance. in 
Finland, Intemet gambling sites are restricted to Finnish adult residents. Anyone wanting to play has to provide their social sectrity number. Although this may stop Finnish adolescent gambling, there is little to stop the Finnish gambling on non-Finnish sites? It Austria, the approach has been to try and control the service providers to stop urwanted material coming in in the first place. This suffers from all the problems of prohibition.

\section{Internet Gambling and Regulatory Issues}

The obvious question to begin with is whether any legal jurisdiction can control Internet gambling? MacMillen (1998) argues there has to be a national approach, as a federal approach will undermine the process. Also, is it a case of controlling gambling or controlling the technology? Here is a list of some of the major problems:

- The industry is setting the pace (the industry understands technology better than governments)

- Non-specific sites cannot be controlled

- Product integrity and consumer protection (lessons to be learned from e-commerce)

- Who sets the standards? Are they enforceable?

- Cross-jurisdictional financial transactions

- Consumers lack confidence in e-commerce. How do you control against illegal operators because it is difficult to identify and detect them?

-- Liability and privacy issues

- Social impacts (underage gambling, problem gambling)

- Impact on other forms of gambling. Cannibalization or complimentarity? As yet there is no market analysis.

-- Constitutional and political constraints

\section{Conclusions}

From a policing and regulatory standpoint, there has to be a pragrnatic approach to sorting out these issues. This needs to involve the industry. There is at present a policy shortfall with more questions than answers. There is the problem of federalism in which nations are divided and competitive. There is little doubt that nations will have to grapple with this proactively. Prohibition is not a realistic option unless it is coordinated nationally (or possible globally). There is the prospect of international conflict as it will be a case of nation versus nation competing for market share and fax revenue. For governmental cooperation there should be (i) agreements with common standards, (ii) collaboration with common laws, (iii) integrity testing and shared knowledge, and (iv) a central authority (global govermment) -- although this may in the final analysis be unworkable. 


\section{References}

BBC News Online (1998). News itern broadcast 23/9/98.

Dwek. R. (1997) "Is on-line gambling on or ofl?" Liscape. May/sunc. p. 48.

Eadington, W. (1998 - July) "The spreat of gaming devices outside of casinos: benefitcost considerations and political backlasin", paper presented at the Third European Association for the Sudy of Gambling Conference. Munich, Germany.

Gunture News (1998) "Police Concerns over "Internet Gambling", t. 17.

Griffiths, M.D. (1998, May) "Gambling into the Millennium: Issues of concern and potential concern", paper presented to GamCare National Conference. London.

Laiho, J. (1998. July) "Legislation and the Internet". paper presented at the Third European Association for the Study of Gambling Conference, Munich, Germany.

McMillen, J. (1998, Jaly) "Interactive Gambling and Society: Thends and 1ssucs", palper presented at the Third European Association for the Study of Gambling Conference, Munich, Germany.

O'Neill, K. (1998, June) "Internet Gambling", paper presented at the 13th National Council on Problem Gambling Conference, lats Vegas, USA.

Tottenham, A. (1996, September\} "Gaming on the Internet", paper presented at the Second European Association for the Study of Gambling Conference, Ansterdam, Holland.

Tottenham, A. (1998, July) "How to control the Internet", paper presented at the Third European Association for the Study of Gambling Conference, Munich, Germany. 